\title{
ASPECTOS RELEVANTES SOBRE O DIAGNÓSTICO DO ZIKA VÍRUS
}

\section{Christiane Oliveira Lima Licínio', Flávio Monteiro Ayres²}

1.Bacharel em Biomedicina e discente no Programa de Mestrado em Ciências Aplicadas a Produtos para Saúde pela Universidade Estadual de Goiás, Goiânia-GO chrislima28@hotmail.com

2.Doutor em Controle de Funções Biológicas e docente do curso de Mestrado Ciências Aplicadas a Produtos para Saúde pela Universidade Estadual de Goiás, Goiânia-GO

Recebido em: 22/09/2018 - Aprovado em: 23/11/2018 - Publicado em: 03/12/2018 DOI: 10.18677/EnciBio 2018B93

O Zika vírus é um RNA vírus envelopado, em sentido positivo e de fita simples. Pertence ao gênero Flavivirus, assim como a Dengue e a Febre Amarela, sendo também classificado como arbovírus devido à transmissão via mosquitos do gênero Aedes. São conhecidas duas linhagens do vírus, a linhagem africana e a linhagem asiática. A doença ficou bastante conhecida depois do surto brasileiro em 2015. Até essa data, apenas dois outros surtos eram conhecidos: em 2007 na ilha Yap e em 2013 na Polinésia Francesa. As consequências mais graves da infecção pelo Zika vírus são a Síndrome de Guillain-Barré e a Síndrome Congênita da Zika, que causou vários casos de microcefalia em neonatos no surto brasileiro. A linhagem encontrada neste surto é a asiática e provavelmente chegou ao país através de imigrantes ilegais e/ou soldados em missão de paz, ambos vindos do Haiti. O diagnóstico da doença é realizado pelos métodos tradicionais de laboratório clínico, como a RTPCR, PCR em tempo real, os métodos sorológicos e PRTN (Teste de neutralização por redução de placa). As reações cruzadas com os demais Flavivirus é bastante comum, devido à semelhança genética entre os vírus, principalmente com o vírus da Dengue. A RT-PCR, PCR em tempo real e PRTN são realizados durante a fase aguda da doença. Os testes sorológicos são realizados tanto na fase aguda (anticorpos do tipo lgM) quanto na fase de convalescência (anticorpo do tipo lgG).

PALAVRAS-CHAVE: Diagnóstico Zika, Microcefalia, Síndrome Guillain-Barrè, Testes sorológicos, Zika vírus.

\section{RELEVANT ASPECTS OF ZIKA VIRUS DIAGNOSIS}

\begin{abstract}
The Zika virus is an enveloped, positive-sense, single-stranded RNA virus. It belongs to the genus Flavivirus, as well as Dengue and Yellow Fever, being also classified as arbovirus due to the transmission via mosquitoes of the genus Aedes. Two lineages of the virus are known, the African lineage and the Asian lineage. The disease became well known after the Brazilian outbreak in 2015. Until that date, only two other outbreaks were known: in 2007 on Yap Island and in 2013 in French Polynesia. The most serious consequences of the Zika virus infection are Guillain-Barré
\end{abstract}


Syndrome and Zika Congenital Syndrome, which caused several cases of microcephaly in neonates in the Brazilian outbreak. The lineage found in this outbreak is Asian and probably arrived in the country through illegal immigrants and / or soldiers on a peace mission, both from Haiti. The diagnosis of the disease is performed by traditional clinical laboratory methods, such as RT-PCR, real-time PCR, serological methods and PRTN (Plaque-reduction Neutralization Test). Crossreaction with other Flaviviruses are quite common, due to the genetic similarity between viruses, especially with the Dengue virus. RT-PCR, real-time PCR and PRTN are performed during the acute phase of the disease. Serological tests are performed both in the acute phase (IgM type antibodies) and in the convalescent phase (IgG type antibody).

KEYWORDS: Microcephaly, Guillain-Barrè Syndrome, Serological Tests, Zika diagnostics, Zika virus.

\section{INTRODUÇÃO}

A grande maioria da literatura científica sobre o Zika Vírus é escassa sobre a disseminação anterior a 2014. Há relatos de um surto na ilha Yap na Micronésia em 2007 e outro na Polinésia Francesa entre 2013 e 2014. Após o aparecimento de casos no Brasil, em 2015, seguidos de relatos de nascimento de crianças com microcefalia em decorrência da contaminação da mãe por Zika Vírus, houve um crescimento significativo de produção científica a respeito desta doença (CALVET et al., 2016).

A epidemia de Zika se alastrou rapidamente pelo Brasil e por mais 50 países no continente americano. Uma doença exantemática não reconhecida foi relatada em dezembro de 2014 no Brasil, mas a confirmação por diagnóstico laboratorial de que se tratava do Zika Vírus, ocorreu a partir de maio de 2015. O vírus se espalhou por toda a região nordeste do país, principalmente nos estados de Pernambuco, Rio Grande do Norte e Bahia. Outros estados também relataram ocorrências, com algumas exceções ao Sul, onde o clima não é favorável ao vetor, e estados de pouca densidade ao Norte (LOWE et al., 2018).

Neste artigo é apresentada uma revisão bibliográfica sobre a infecção por Zika Vírus, enfatizando as particularidades do vírus, a infecção pelo vírus e as metodologias de diagnóstico. O banco de dados Pubmed foi utilizado para a pesquisa de artigos científicos de livre acesso, em língua inglesa. O período de publicação entre 2015 e 2018 foi delimitado, com o intuito de selecionar os mais atuais e relevantes artigos sobre o tema, visto se tratar de assunto mais disseminado a partir de 2015. DECS e MESH foram usados para encontrar os descritores "Zika Virus" ou "microcephaly" ou "Guillain-Barrè syndrome" ou "serologicals tests" ou "Zika diagnostics". As publicações foram selecionadas pelo contexto como tratavam o tema, sendo excluídos os artigos que não traziam informações sobre diagnóstico. Foram incluídos artigos que tratavam das particularidades do vírus e da infecção.

\section{PARTICULARIDADES DO ZIKA VÍRUS}

O Zika Vírus foi descoberto em 1947, a partir de macacos da espécie Rhesus provenientes da Floresta Zika, em Uganda, quando pesquisadores estudavam sobre a Febre Amarela. Neste estudo, foi identificada a presença do vírus em mosquitos do gênero Aedes, coletados na mesma floresta. O Zika Vírus pertence ao gênero Flavivirus assim como Dengue Vírus (DENV) e Febre Amarela (YFV). Também foi 
classificado como sendo um arbovírus (arthropod-borne vírus), que são os vírus transmitidos aos humanos via artrópodes hematófagos, como o mosquito (MUSSO; GUBLER, 2016).

Os Flavivirus são RNA vírus envelopados, em sentido positivo, de fita simples (FOCOSI et al., 2016; MUSSO; GUBLER, 2016). Ao contaminar a célula hospedeira, - RNA viral é traduzido em um polipeptídio no citoplasma celular, sendo posteriormente processado pelas proteases do hospedeiro em três proteínas estruturais - envelope, capsídeo e precursor de membrana - e em sete proteínas não estruturais - NS1, NS2A, NS2B, NS3, NS4A, NS4B e NS5 - (Figura 1) (FOCOSI et al., 2016; MUSSO; GUBLER, 2016; RASTOGI et al., 2016; SHANKAR et al., 2017).

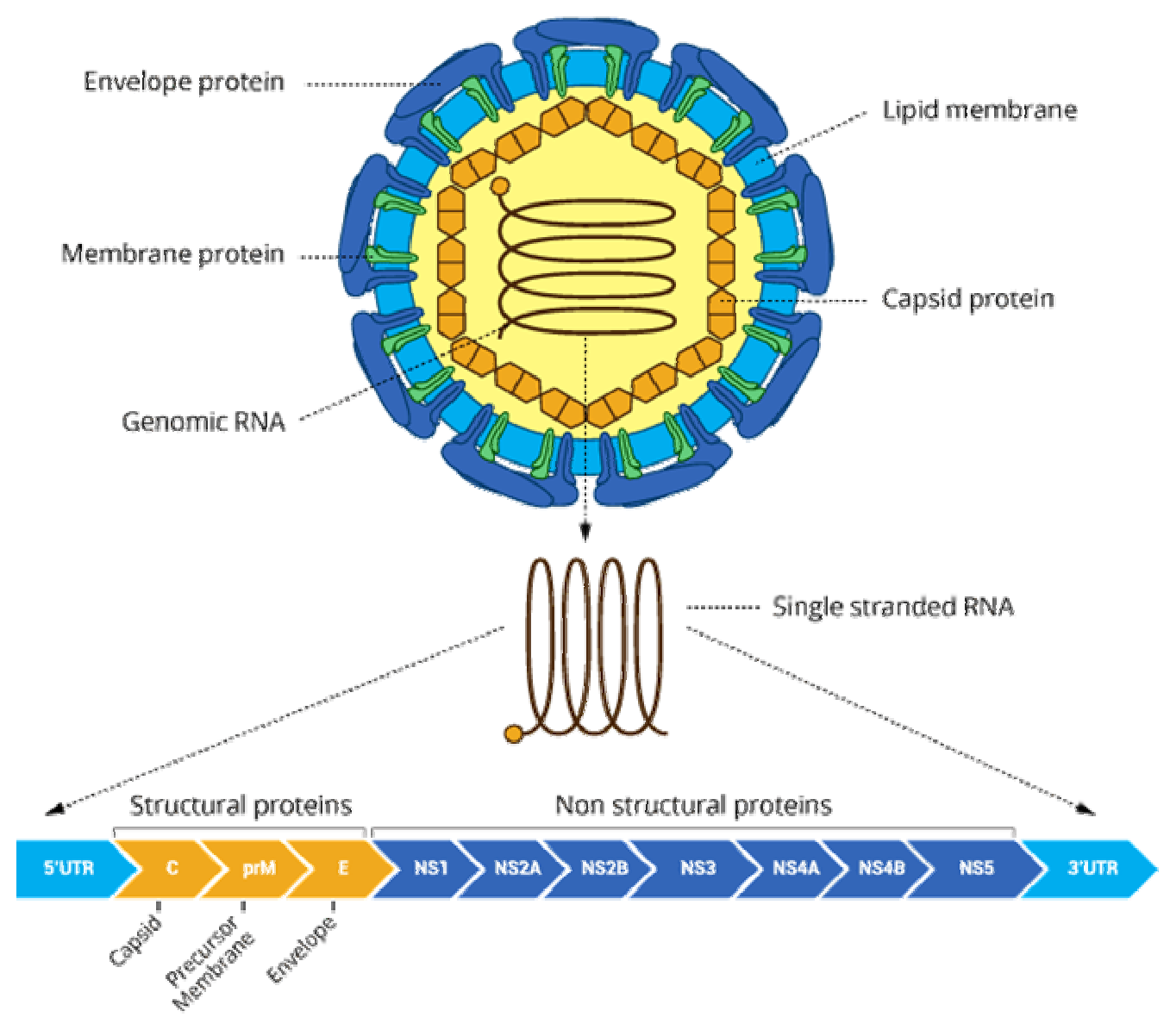

FIGURA 1 - Estrutura detalhada do Zika Vírus

Fonte: https://www.promega.com.br/resources/pubhub/inspiration/zika-perspectives-responses/

A proteína NS1 é responsável pela replicação viral e é diretamente ligada à indução do sistema imune. Algumas regiões da proteína NS1 são idênticas entre os Flavivirus, o que causa a maioria das reações cruzadas nos ensaios que utilizam essa proteína como antígeno (RASTOGl et al., 2016). As reações cruzadas são entre os ZIKV, Dengue Vírus, Febre Amarela, West Nilo Vírus ou Vírus da Encefalite Japonesa, principalmente com o DENV, são devido às suas semelhanças filogenéticas (Figura 2) (MUSSO; GUBLER, 2016). 


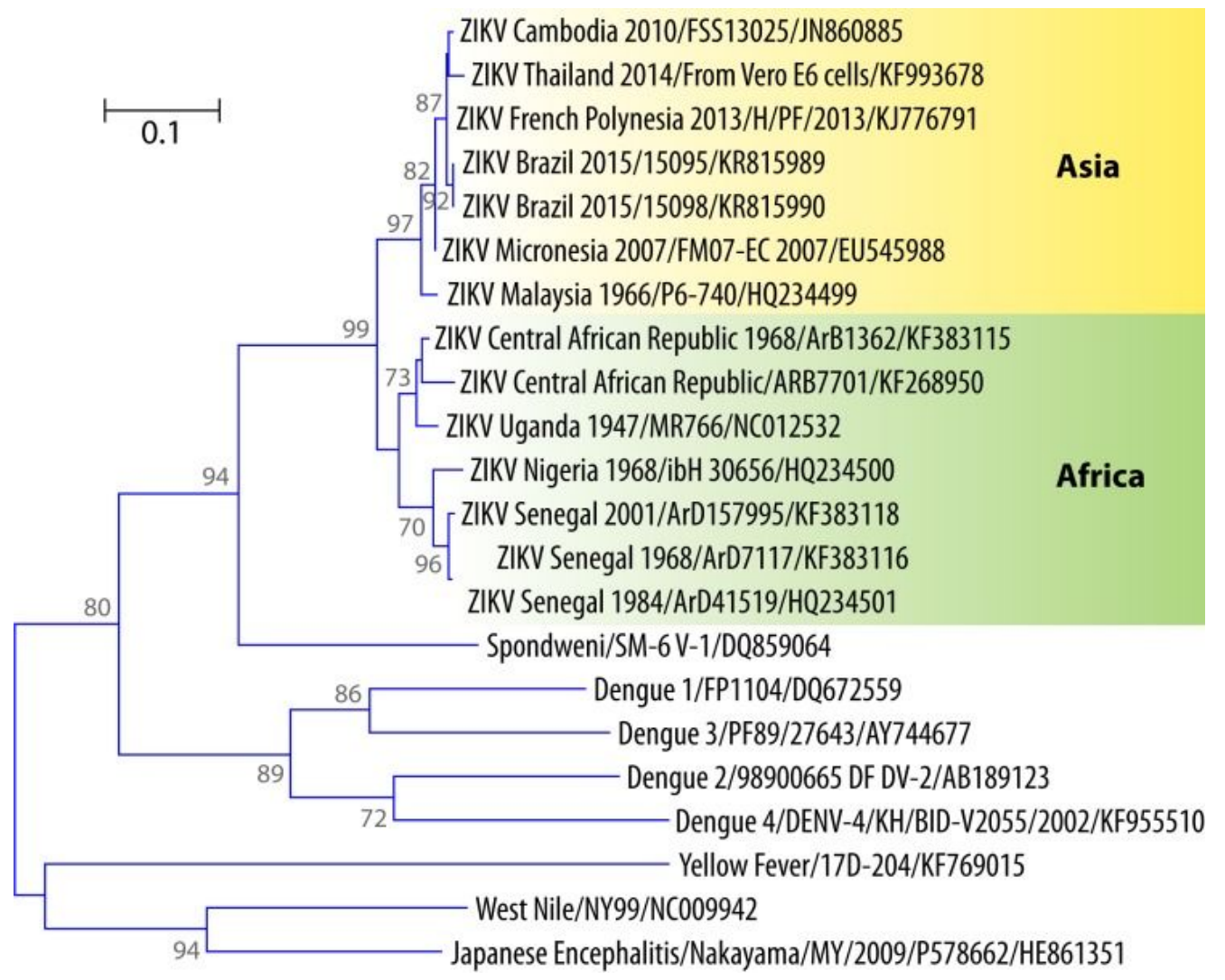

FIGURA 2 - Árvore Filogenética do Zika Vírus

Fonte: Musso (2016)

Três genótipos de Zika Vírus são conhecidos - Oeste Africano, Leste Africano e Asiático - derivados de duas linhagens - Africana e Asiática (FOCOSI et al., 2016; MUSSO; GUBLER, 2016; LEE et al., 2017; LOWE et al., 2018), sendo que essa distinção entre os três genótipos foi esclarecida após a completa descrição da região codificante ligado à proteína NS5 (MUSSO; GUBLER, 2016). O genoma da linhagem africana (ZIKV MR 766) foi decifrado em 2007, contudo o genoma da linhagem asiática também já está disponível em bancos de dados on line. Com uso de recursos computadorizados, as duas linhagens foram comparadas e a semelhança entre elas é de $88,9 \%$ (MUSSO; GUBLER, 2016).

A região próxima ao glicano Asn154 da glicoproteína E, responsável pela ligação do vírus à célula hospedeira, é a parte estrutural do ZIKV que mais se distancia do DENV. Tal glicano é citado como sendo o responsável pela neurovirulência em cepas de vírus West Nilo. Em laboratório, ratos infectados com cepas sem esse glicano apresentaram baixa neurovirulência (BOEUF et al., 2016).

A princípio, três teorias sobre a introdução do Zika Vírus no Brasil foram formuladas:

a) a primeira é de que o vírus foi introduzido durante a Copa do Mundo de 2014;

b) a segunda é de que ocorreu durante um evento de Canoagem em 2014 no Rio de Janeiro, em que um atleta oriundo da Ásia estivesse com a viremia;

c) a última hipótese seria de que a introdução ocorreu em 2013, nos jogos da Copa das Confederações (CALVET et al., 2016). 
Um estudo filogenético realizado pela Fiocruz Pernambuco, com 4.035 amostras de genomas dos vírus Zika, Dengue e Chikungunya, evidenciou que a introdução do Zika Vírus não ocorreu pelas três hipóteses acima, e sim por cepas da América Central, especificamente do Haiti. Sendo assim, a introdução do vírus em solo brasileiro teria ocorrido por imigrantes ilegais e por militares que atuaram em missões no Haiti. (CAMPOS et al., 2018).

A linhagem encontrada no surto brasileiro de 2015 é a asiática, sendo 99\% compatível ao vírus circulante na Polinésia Francesa em 2013 (MUSSO; GUBLER, 2016; SHANKAR et al., 2017; LOWE et al., 2018). Esta possui grande virulência e foi responsável pelo surto mais negativo, em relação às consequências da infecção. $A$ hipótese a esse fato é de que, pela grande incidência do vírus nos surtos brasileiro (acima de 1.000 .000 casos) e na Polinésia Francesa (acima de 30.000 casos), a frequência da Síndrome de Guillain-Barrè (em ambos os surtos) e de microcefalia (surto brasileiro) foi mais evidente (FREIRE et al., 2015; CALVET et al., 2016; MUSSO; GUBLER, 2016; LOWE et al., 2018). Sendo assim, em surtos pequenos como nas llhas Cook em março de 2014, onde foram relatados 905 casos, não se excluiu o fato da cepa não ser capaz de provocar as síndromes, apenas não houve casos em número suficiente para uma maior manifestação (MUSSO; GUBLER, 2016).

Não há relatos de grandes surtos com a linhagem africana, sendo os números de casos na África inferiores ao restante do planeta e sem relatos de agravamento da doença, como o ocorrido no Brasil (FREIRE et al., 2015; MUSSO; GUBLER, 2016). Outra hipótese sobre a virulência distinta entre as cepas de ZIKV é de que a viremia em humanos é menor quando infectados pela linhagem africana, em decorrência do pouco sucesso desta linhagem nos mosquitos $A$. aegypti (FREIRE et al., 2015).

\section{INFECÇ̃̃ PELO ZIKA VÍRUS}

Inicialmente, a contaminação pelo vírus pode não ter sido notada pelos sintomas serem bastante semelhantes aos causados pela Dengue. O surto de Zika Vírus chamou a atenção das autoridades sanitárias quando houve a associação entre a infecção pelo vírus e os casos de microcefalia em neonatos (Síndrome Congênita da Zika) e as desordens neurológicas (Síndrome de Guillain-Barrè) (CALVET et al., 2016).

Os principais sintomas clínicos da doença são: erupção macular ou maculopapular com presença de prurido, dor de cabeça, artralgia, mialgia, prostração, conjuntivite não-purulenta, e pode ou não estar associada a febre baixa. Os casos assintomáticos contabilizam $80 \%$, o que dificulta um levantamento epidemiológico satisfatório em relação à doença. Os relatos de morte em decorrência da Zika são escassos, sendo três casos relatados até maio de 2016 no Brasil (CALVET et al., 2016). As duas condições severas em decorrência da infecção pelo ZIKV envolvem danos neurológicos:

a) Síndrome de Guillain-Barrè (GBS) - os nervos periféricos do paciente são atacados pelo seu sistema imune;

b) Síndrome Congênita do Zika (CSZ) - vários espectros de má formação neurológica durante o desenvolvimento fetal, ainda em avaliação das várias consequências e sequelas ao longo do tempo. Primeira evidência do surto foi a microcefalia, caracterizada pela diminuição do perímetro cefálico (LOWE et al., 2018). 
Os sintomas clínicos e os achados laboratoriais mais simples, trombocitopenia e leucopenia no hemograma ou alterações nas transaminases hepáticas, são típicos de várias outras doenças causadas por arbovírus, principalmente Dengue (DENV) e Chikungunya (CHIKV). Atualmente, nove doenças com essas características são circulantes no Brasil: Dengue, Chikungunya, Febre Amarela, Vírus da Encefalite Saint Louis, Mayaro, Oropouche, Vírus West Nilo, sendo essa última raríssima com apenas um caso relatado no país (MUSSO; GUBLER, 2016; FELIX et al., 2017). De todas essas doenças, Febre Amarela, DENV e CHIKV são as mais relevantes quanto ao diagnóstico, pelo grande número de casos das três doenças em território brasileiro, sendo todas, incluindo o ZIKV, co-circulantes e transmitidas pelo mesmo vetor, os mosquitos Aedes aegypti e Aedes albopictus (MUSSO; GUBLER, 2016; MAGALHAES et al., 2017; LOWE et al., 2018).

Uma pesquisa realizada em Recife, entre 2015 e 2016, logo após a epidemia de Zika na região, identificou que $60 \%$ dos pacientes que apresentavam sintomas semelhantes à Dengue estavam, na verdade, com infecções de Zika ou Chikungunya (MAGALHÃES et al., 2017). Apesar de que um grande número de casos de Dengue foi notificado nessa área em 2015, os ensaios moleculares e sorológicos realizados comprovaram que a incidência dessa doença caiu com o surgimento dos casos de Zika e Chikungunya no mesmo período. Com a diminuição dos casos de Zika em setembro de 2015, o número de casos de Chikungunya começou a subir. Tal conclusão indica que o diagnóstico de arboviroses utilizando a clínica do paciente nem sempre reflete a real causa da infecção, visto que ao menos três doenças estão circulantes na mesma região. Ao diagnosticar a doença com auxílio dos ensaios laboratoriais, pode-se inferir em reações cruzadas entre os Flavivirus (MAGALHÃES et al., 2017).

Não há um consenso sobre a quantidade de pessoas contaminadas pelo ZIKV. A Organização Mundial de Saúde diz que o padrão-ouro para estimar a incidência cumulativa de soroprevalência numa população, é o desenvolvimento de um estudo longitudinal das amostras de indivíduos em fase aguda e convalescência da infecção, o que durante um surto é muito difícil de acompanhar, principalmente em estágios iniciais. Com isso o número exato de pessoas contaminadas pelo Zika Vírus é desconhecido. Outro método é um estudo transversal de pacientes antes do surto e depois do surto e prever a incidência cumulativa. Esse tipo de estudo foi usado no caso do surto de H1N1 (WHO, 2016).

Dentre as arboviroses, somente a Zika tem a transmissão também via sexual e vertical, de mãe para o feto (LOWE et al., 2018). A transmissão vertical foi verificada através da barreira placentária, durante o parto com o contato do bebê e os fluidos maternos, e durante a amamentação, visto que o vírus foi encontrado no leite materno (SHANKAR et al., 2017). Após a descoberta da via sexual da transmissão viral, houve grande disseminação de casais que passaram a evitar a concepção neste período, receosos de serem atingidos pela infecção. Assim, o CDC (Centre of Disease Control and Prevention - Agência de Saúde Norte Americana) declarou que os casais que haviam sofrido com uma infecção de Zika vírus, deveriam esperar ao menos 180 dias para a concepção, já que foi encontrado material genético do vírus em sêmen depois de 188 dias de infecção e em secreção vaginal após oito semanas (LOWE et al., 2018).

Pesquisadores encontraram indícios de que a mutação sofrida pelo ZIKV na natureza contribuiu para o aumento da patogenicidade do vírus, tornando-o apto a uma disseminação explosiva. As proteínas NS1, NS3 e NS5 são prioritariamente 
mais ligadas ao reconhecimento dos Flavivirus após a infecção. Porém, após uma infecção por DENV, a proteína NS5 promove uma maior ativação das células $T$ no hospedeiro. Tal fato comprova uma grande reação cruzada entre o vírus da Dengue e o da Zika (DELGADO et al., 2018).

Há relatos sobre a imunidade cruzada entre o ZIKV e outras infecções por Flavivirus, principalmente o DENV. A rápida disseminação do ZIKV geograficamente em alguns meses, em contraponto ao longo tempo que o DENV levou para a mesma disseminação, provavelmente é devido a esse fato (LOWE et al., 2018). As proteínas NS1 dos vírus, responsáveis pela invasão dos vírus nos linfócitos T CD4 e CD8, além de serem geneticamente semelhantes, induzem o reconhecimento dos mesmos epítopos nas células B. Tal fato explicaria o agravamento de uma infecção secundária por ZIKV em pessoas previamente infectadas por DENV (FREIRE et al., 2015; DELGADO et al., 2018). O aprimoramento dependente de anticorpos (ADE antibody-dependent enhancement) do ZIKV como infecção secundária, seria semelhante ao que acontece nas infecções pelos diversos sorotipos de DENV (DELGADO et al., 2018). A infecção prévia por DENV influencia na qualidade dos anticorpos produzidos ao ZIKV. Os anticorpos policlonais do ZIKV como infecção primária são altamente específicos, o que causa baixa reação cruzada com outros Flavivirus (ROTH et al., 2018).

A qualidade de anticorpos anti-DENV, secundários a uma infecção prévia por ZIKV, não é recíproco. Esse fato foi evidenciado após o surto de ZIKV em 2015, em que os números de infectados por DENV sofreram uma queda. Em um estudo realizado entre 2009 e 2017, a proporção de soropositividade em amostras testadas para DENV caiu de 37\% para 8\% (RIBEIRO et al., 2018). Em camundongos imunodeficientes, a prévia imunização pelo ZIKV fez com que a infecção por DENV fosse ainda mais severa, indicando que muito ainda deve ser avaliado para o desenvolvimento de uma vacina contra o ZIKV (ROTH et al., 2018).

A prevenção à doença é feita como as demais arboviroses, que não possuem vacina. A principal medida é o controle do mosquito vetor (MUSSO; GUBLER, 2016). A maioria das medidas preventivas são também medidas de saneamento básico. A aplicação de inseticidas e larvicidas não têm se mostrado eficaz. Uma outra medida, que se mostra promissora, mas ainda sem resultados visíveis, são os mosquitos geneticamente alterados. Alguns são infectados por uma bactéria (Wolbachia) e se tornam estéreis (LOWE et al., 2018).

A vacina contra o ZIKV está em desenvolvimento. São várias linhas de estudo em andamento ao mesmo tempo, a maioria focando a proteína do envelope do vírus. Recentemente, alguns pesquisadores focaram o desenvolvimento da vacina através da proteína NS1 e outros tentam desenvolver uma semelhante à vacina da febre amarela, com o vírus atenuado (KWEK et al., 2018).

\section{DIAGNÓSTICOS DO ZIKA VÍRUS}

Devido aos sintomas da doença causados pelo ZIKV serem inespecíficos, facilmente confundidos com os de outras arboviroses, o diagnóstico clínico diferenciando das doenças é difícil. Com isso, o diagnóstico laboratorial diferencial é necessário, principalmente em áreas endêmicas ou de circulação de vários arbovírus ao mesmo tempo (SHANKAR et al., 2017). A presença do vírus em várias matrizes amostrais, como soro, plasma, urina, saliva, fluido amniótico, leite materno, sêmen e secreção vaginal, facilita o desempenho de exames laboratoriais (CALVET et al., 2016). 
O diagnóstico laboratorial da Zika é feito com as metodologias usadas e já usuais para outras arboviroses. O genoma viral é detectado por metodologias moleculares e os anticorpos, tanto na fase aguda (IgM) quanto na convalescência (IgG), por métodos sorológicos (CALVET et al., 2016; WAGGONER; PINSKY, 2016; SHANKAR et al., 2017).

O diagnóstico molecular é feito pela detecção do RNA viral nas amostras humanas, utilizando a técnica de PCR-RT (reação de cadeia polimerase transcriptase reversa) em duas etapas: i) transcrição reversa do RNA em DNA de fita simples (cDNA); ii) conversão em DNA de fita dupla e sua amplificação (MUSSO; GUBLER, 2016). Comercialmente, vários kits foram desenvolvidos com essa metodologia, focando a região codificante da proteína NS5 no gene dos Flavivirus, ou as regiões codificantes da proteína E do envelope viral e da proteína NS3 (FOCOSI et al., 2016).

A PCR em tempo real, uma variação do RT-PCR, aprimorou a técnica ao ser realizado em apenas uma etapa e incluiu uma sonda fluorescente. Além disso, há uma variação da PCR em tempo real em que é possível quantificar o genoma viral nos fluidos orgânicos. Essa variação metodológica de amplificação de ácidos nucléicos é chamada de qRT-PCR (MUSSO; GUBLER, 2016). Vários estudos realizados com a $P C R$ em tempo real demonstraram que essa técnica é mais sensível e específica que a RT-PCR e produz menor quantidade de falsos-positivos (SINGH et al., 2018).

Ambas as técnicas se mostraram bem sucedidas na detecção do genoma viral do ZIKV quando realizadas em amostras da fase aguda da doença. Apesar de ser uma forma definitiva de diagnóstico, as técnicas moleculares se limitam à primeira semana de sintomas da doença (CALVET et al., 2016). No sangue, o RNA viral se mostra presente por um breve período de tempo - de três a cinco dias após o início dos sintomas clínicos. Na urina, o RNA viral permanece por mais de 10 dias e no sêmen por mais de dois meses (FOCOSI et al., 2016).

A técnica molecular é bastante sensível, porém pouco específica, já que os primers utilizados são os mesmos para os diversos Flavivirus circulantes, e isso causa a ocorrência de resultados falso-negativos (MUSSO; GUBLER, 2016). Baixa viremia também pode causar a ocorrência de falso-negativos, o que pode acontecer com frequência devido ao curto período de presença do vírus no sangue. Outro ponto negativo ao uso desta técnica são os altos custos com equipamentos, reagentes, pessoal especializado e o tempo consumido para o ensaio, o que dificulta a disseminação em vários laboratórios (CALVET et al., 2016).

O diagnóstico sorológico tem o diferencial em relação ao diagnóstico molecular por ser possível a detecção da doença também no período de convalescência. $O$ marcador de infecção aguda (IgM) pode ser encontrado no sangue contaminado entre três a cinco dias após o início dos sintomas, se estendendo por até dois meses. A soroconversão é a etapa mais confiável de detecção dos anticorpos e se inicia após o sétimo dia após início dos sintomas (CALVET et al., 2016). O marcador de infecção $\lg G$ é detectado a partir da soroconversão e é classificado como uma imunidade definitiva, pois sua produção pelo organismo é de longa duração. A produção dos anticorpos lgG é mantida em níveis detectáveis por pelo menos três meses. Em casos em que a investigação é feita após o fim da fase aguda da infecção, apenas os anticorpos do tipo lgG serão encontrados (NICOLINI et al., 2017). A Figura 3 demonstra, ao longo da infecção por ZIKV, as oportunidades de diagnóstico molecular e sorológico. 
O problema relacionado aos testes sorológicos é o alto índice de reações cruzadas com as doenças causadas por outras arboviroses, principalmente pelo DENV. A reação cruzada é ainda mais intensa nas áreas endêmicas. Os resultados dos testes sorológicos devem ser avaliados com muito cuidado, com intuito de evitar os resultados falso-positivos. Mesmo em pacientes que não tiveram contato com infecções por arbovírus, mas foram vacinados contra febre amarela, a reação cruzada nos testes sorológicos pode acontecer (CALVET et al., 2016; MUSSO; GUBLER, 2016).

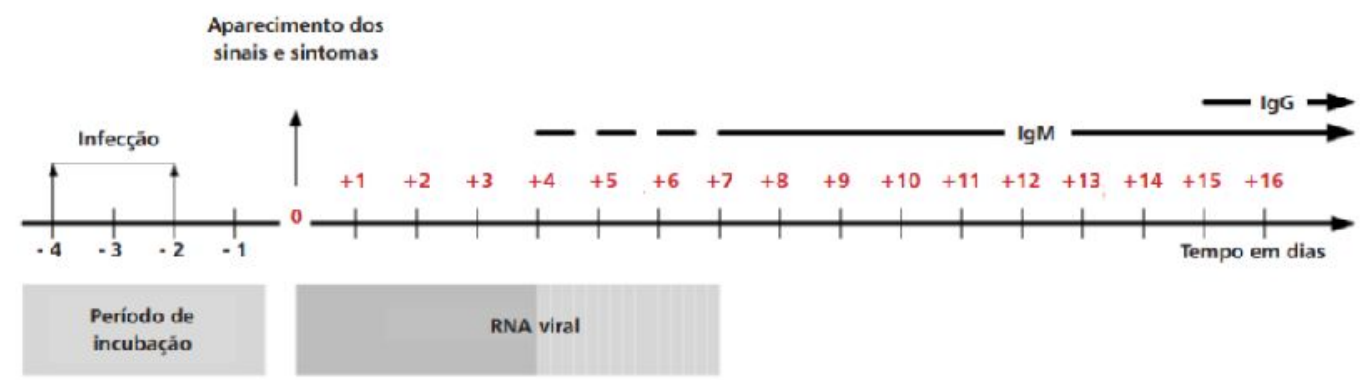

FIGURA 3 - Oportunidade de detecção do Zika vírus, segundo a metodologia laboratorial. Fonte: SAÚDE (2016) http://combateaedes.saude.gov.br/images/sala-desituacao/Microcefalia-Protocolo-de-vigilancia-e-resposta-10mar2016-18h.pdf, acesso em 21/09/2018.

O aparecimento de anticorpos IgG em infecções secundárias por Flavivirus é mais rápido do que em infecções primárias. Tais anticorpos surgem quase que imediatamente ao surgimento dos anticorpos IgM. Esse fato acontece principalmente quando a infecção primária foi por DENV e a secundária é por ZIKV (NICOLINI et al., 2017). Com isso, as agências de saúde dos países envolvidos nos surtos de ZIKV e/ou DENV, criaram algoritmos para o diagnóstico dessas doenças, nos casos em que haja a infecção secundária. Apenas o diagnóstico sorológico pode não ser suficiente para a identificação do patógeno, indicando a necessidade de realização de testes em outra metodologia para a diferenciação (CALVET et al., 2016; WAGGONER; PINSKY, 2016). A Figura 4 demonstra o algoritmo usado pelo Ministério da Saúde brasileiro.

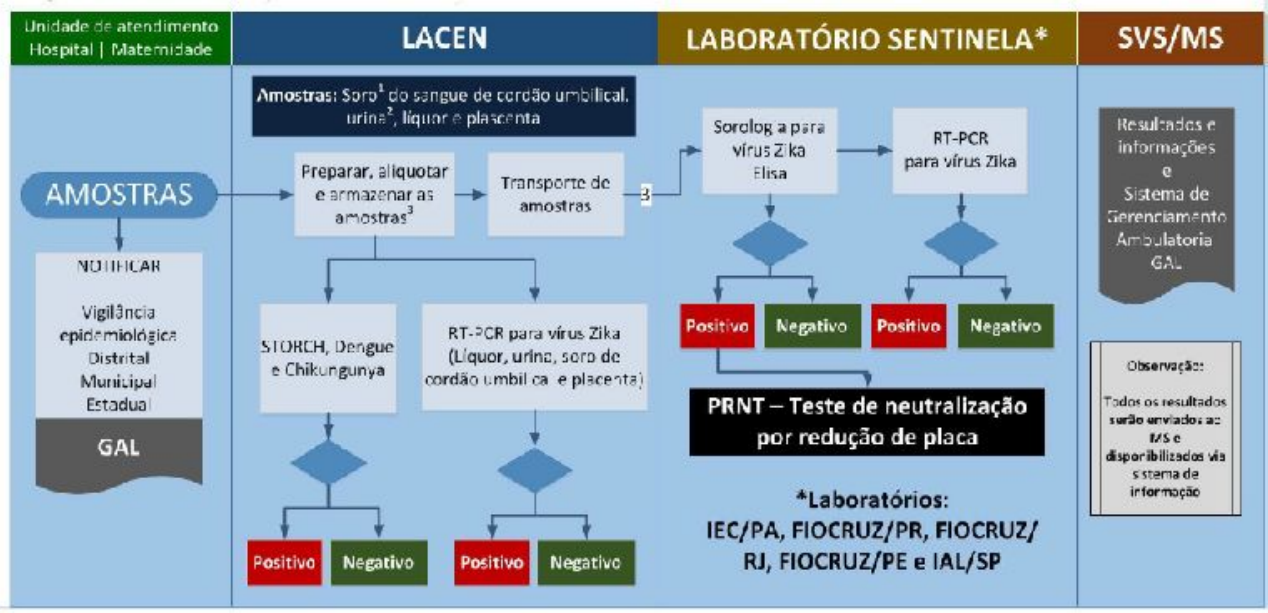

1. As amostras de suro devem ser submetidas às análises para Dengue, Chikungunya e STORCH (Sif lis, Toxoplasmose, Rubéola, Citomegalovírus e Herpes)

2. As a mostras de urina se-åo co etadas apenas em gestartes para realização de diagnóstico por RT-PCF.

3. Lacen que não realizar RT-PCR para virus Zi ‘a, encaminhar ao Laboratório Sentinela de sua área.

FIGURA 4 - Algoritmo laboratorial para amostras suspeitas de microcefalia relacionada ao Zika Vírus - Rede Pública de Saúde

Fonte: SAÚDE (2016) http://combateaedes.saude.gov.br/images/sala-de-situacao/MicrocefaliaProtocolo-de-vigilancia-e-resposta-10mar2016-18h.pdf, acesso em 21/09/2018. 
A técnica PRTN (Teste de neutralização por redução de placa) é o padrão-ouro para a diferenciação da reação cruzada entre os anticorpos produzidos em infecções por Flavivirus (CALVET et al., 2016; MUSSO; GUBLER, 2016). Esse teste é geralmente usado como secundário ao diagnóstico molecular e testes de ELISA (sorológico) e testa a capacidade dos anticorpos da amostra em neutralizar o vírus suspeito da infecção. A amostra é testada em diluições seriadas em conjunto com uma suspensão do vírus (ZIKV ou DENV ou febre amarela, por exemplo) e a mistura é adicionada a uma cultura de células. Após um período de sete dias de incubação, são contadas as unidades formadoras de placas (PFU) e a titulação é determinada pela diluição realizada (NICOLINI et al., 2017).

Apesar de ser um método muito sensível e muito específico, mais do que a metodologia ELISA, a realização é demorada, requer pessoal e dependências físicas especializadas, de alto custo. Com isso, a realização destes testes é restrita (CALVET et al., 2016; MUSSO; GUBLER, 2016; NICOLINI et al., 2017). A SBPC/ML (Sociedade Brasileira de Patologia Clínica e Medicina Laboratorial) desenvolveu um algoritmo a ser usado pelos laboratórios da rede particular, a fim de auxiliar 0 diagnóstico laboratorial para o ZIKV. A Figura 5 demostra esse algoritmo (SBPC/ML, 2016).

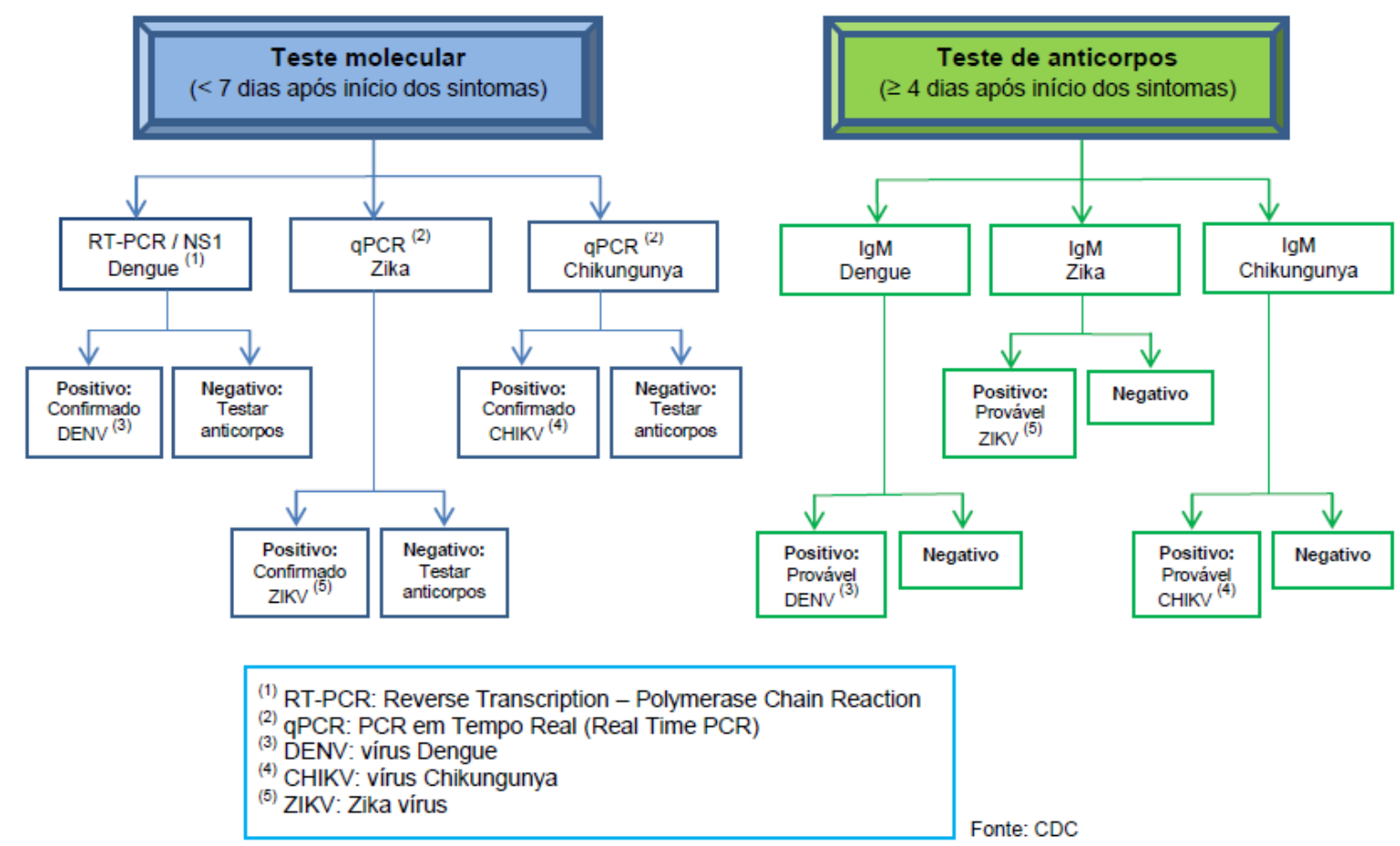

FIGURA 5 - Algoritmo de testes para detecção de arbovírus em casos de suspeita de Zika, Chikungunya ou Dengue - Rede Particular de Saúde.

Fonte: SBPC/ML (2016)

A detecção de anticorpos IgG é muito importante nos casos de mulheres grávidas com suspeita de infecção pelo ZIKV ou em momentos de surto. Mesmo em casos assintomáticos ou em que o RNA viral não foi encontrado, a presença destes anticorpos no sangue materno pode indicar uma infecção congênita e, possivelmente casos de microcefalia (SINGH et al., 2018). Além disso, devido a baixa viremia em vários casos da infecção, inviabilizando o diagnóstico molecular, a sorologia é a melhor opção ao diagnóstico. A sorologia é um método barato, ENCICLOPÉDIA BIOSFERA, Centro Científico Conhecer - Goiânia, v.15 n.28; p.1172 
confiável e robusto, além de permitir a vigilância epidemiológica e ser de fácil manuseio durante surtos (CALVET et al., 2016; MUSSO; GUBLER, 2016; SINGH et al., 2018). A tabela 1 resume as vantagens e desvantagens das metodologias para diagnóstico do ZIKV.

QUADRO 1 - Vantagens e Desvantagens das Metodologias de Diagnóstico para Zika vírus

\begin{tabular}{|c|c|c|}
\hline METODOLOGIA & VANTAGENS & DESVANTAGENS \\
\hline Ensaios sorológicos & $\begin{array}{c}\text { Fácil desempenho } \\
\text { Custo acessível dos kits } \\
\text { Automação acessível } \\
\text { Baixo tempo para execução } \\
\text { Alta sensibilidade }\end{array}$ & $\begin{array}{l}\text { Reações cruzadas } \\
\text { Poucos kits disponíveis } \\
\text { Falsos-positivo }\end{array}$ \\
\hline RT-PCR & $\begin{array}{l}\text { Alta especificidade } \\
\text { Alta precisão }\end{array}$ & $\begin{array}{l}\text { Reações cruzadas } \\
\text { Falsos-negativos } \\
\text { Alto custo kits } \\
\text { Alto custo automação } \\
\text { Restrito à } 1^{\underline{a}} \text { semana }\end{array}$ \\
\hline PCR em tempo real & $\begin{array}{c}\text { Alta especificidade } \\
\text { Alta precisão } \\
\text { Quantificação viral } \\
\text { Rapidez na execução } \\
\text { Menos falsos-negativo }\end{array}$ & $\begin{array}{l}\text { Reações cruzadas } \\
\text { Alto custo kits } \\
\text { Alto custo automação } \\
\text { Restrito à } 1^{1 \beth} \text { semana }\end{array}$ \\
\hline PRTN & $\begin{array}{c}\text { Alta especificidade } \\
\text { Alta sensibilidade } \\
\text { Diferenciação entre Flavivirus }\end{array}$ & $\begin{array}{c}\text { Alto custo } \\
\text { Pessoal especializado } \\
\text { Infraestrutura } \\
\text { especializada } \\
\text { Longo tempo execução }\end{array}$ \\
\hline
\end{tabular}

Fonte: LICÍNIO (2018)

A maioria dos produtos para diagnóstico sorológico disponíveis no mercado mundial usam antígenos NS1 (non-structure protein 1), NS5 e proteína E do vírus Zika, em busca de aumentar a especificidade dos kits. Com isso, o índice de falsopositivos seria diminuído (NICOLINI et al., 2017). Destes, as proteínas do envelope viral são as que mais causam reação cruzada, principalmente com o DENV, o que torna o produto muito sensível, porém pouco específico. Os que utilizam a proteína NS1 como antígeno possuem a sensibilidade e especificidade adequadas, com baixo índice de reação cruzada (LUSTIG et al., 2017).

A proteína NS1 é encontrada circulante no sangue independente se é uma infecção primária ou secundária (RASTOGI et al., 2016). Os testes sorológicos que usam a proteína NS1 recombinante possuem menor índice de reações cruzadas, principalmente com o DENV (SINGH et al., 2018).

A proteína NS1 é encontrada circulante no sangue desde o primeiro dia de infecção e dura até o início da soroconversão $\lg M$ para $\lg G$. A identificação de fragmentos não comuns aos demais Flavivirus é uma forma de diminuir a reação cruzada entre os demais vírus, vez que identificará de forma específica os anticorpos produzidos pelo organismo após a infecção pelo Zika Vírus, e de forma 
precoce, já que a proteína se expressa no início da infecção (FERREIRA et al., 2016).

A identificação de epítopos não comuns aos demais Flavivirus é uma forma de diminuir a reação cruzada entre os demais vírus. Vários pesquisadores estão em esforços para alcançar tais epítopos, e concentram-se na proteína $E$ para esse fim (NICOLINI et al., 2017). Testes de metodologia MIA (ensaios multiplex de microesferas) estão sendo desenvolvidos, com a inclusão dos antígenos da proteína E, NS1 e NS5. Isso aumenta a sensibilidade e a especificidade do teste (SINGH et al., 2018).

\section{CONSIDERAÇÕES FINAIS}

Há vários impactos sociais e econômicos em decorrência do surto de Zika vírus de 2015 no Brasil. O primeiro deles é a grande quantidade de crianças com microcefalia ou outros problemas de nascimento, devido à Síndrome Congênita da Zika, trazendo impactos ao desenvolvimento da criança, envolvendo a sua família e toda a comunidade ao seu redor, uma vez que as limitações são diversas. O surto de ZIKV já não é mais uma emergência em saúde pública no Brasil. Porém, as sequelas deste primeiro evento ainda ressoarão por um longo período, devido aos impactos na sociedade e nas famílias atingidas pelas formas mais severas de consequências à infecção.

O controle da doença ainda passa pelo controle do vetor, o que tem se mostrado ineficiente, já que o mesmo vetor transmite a DENV, que ano após ano ressurge na estação chuvosa no país. Isto pode estar intimamente atrelado ao fato de que a grande maioria dos diagnósticos serem feitos baseando-se apenas na clínica do infectado, não havendo um diagnóstico diferencial efetivo. Isso dificulta as autoridades sanitárias a instituir programas de prevenção mais eficientes, de previsão de ressurgimento de novos surtos e epidemias.

O diagnóstico da infecção pelo ZIKV é demasiadamente importante, mesmo em momentos em que há controle de surtos e menos casos de infecção detectados. Isso se deve ao grande impacto sócio-econômico causado pelos casos de microcefalia em neonatos, além da suma necessidade de diferenciação entre as demais arbovirores. As reações cruzadas entre as arboviroses ainda é um empecilho ao diagnóstico preciso. Mesmo os testes de PCR-RT podem causar resultados falsos, devido à semelhança genética entre os vírus. Os ensaios sorológicos, que custam menos, possuem técnica mais simplificada e usam equipamentos mais baratos, são os testes mais acessíveis. Apesar de que existem epítopos sendo usados para minimizar a reação cruzada, ela ainda não é completamente descartada nessa metodologia. Não há vacina contra o Zika vírus e o controle da infecção é ainda uma questão de medidas de saneamento básico.

\section{AGRADECIMENTOS}

O presente trabalho foi realizado com apoio da Fundação de Amparo à Pesquisa do Estado de Goiás - processo número 201810267000572.

\section{REFERÊNCIAS}

BOEUF, P.; DRUMMER, H. E.; RICHARDS, J. S.; SCOULLAR, M. J. L.; BEESON, J. G. The global threat of Zika virus to pregnancy: Epidemiology, clinical perspectives, mechanisms, and impact. BMC Medicine, v. 14, n. 1, p. 0-9, 2016. Disponível em: $<$ http://dx.doi.org/10.1186/s12916-016-0660-0>. 
CALVET, G. A.; DOS SANTOS, F. B.; SEQUEIRA, P. C. Zika virus infection: Epidemiology, clinical manifestations and diagnosis. Current Opinion in Infectious Diseases, v. 29, n. 5, p. 459-466, 2016. Disponível em: <https://insights.ovid.com/pubmed?pmid=27496713>.

CAMPOS, T. D. L.; DURÃES-CARVALHO, R.; REZENDE, A. M. Revisiting Key Entry Routes of Human Epidemic Arboviruses into the Mainland Americas through LargeScale Phylogenomics. International Journal of Genomics, 2018. Disponível em: $<$ https://www.hindawi.com/journals/ijg/aip/6941735/>.

DELGADO, F.; TORRES, K.; CASTELLANOS, J.; ROMERO-SÁNCHEZ, C.; SIMONLORIĖRE, E.; et al.,. Improved Immune Responses Against Zika Virus After Sequential Dengue and Zika Virus Infection in Humans. Viruses, v. 10, n. 9, p. 480, 2018. Disponível em: <http://www.mdpi.com/1999-4915/10/9/480>.

FELIX, A. C.; SOUZA, N. C. S.; FIGUEIREDO, W. M.; COSTA, A. A.; INENAMI, M.; et al.,. Cross reactivity of commercial anti-dengue immunoassays in patients with acute Zika virus infection. Journal of Medical Virology, v. 89, n. 8, p. 1477-1479, 2017. Disponível em: <https://doi.org/10.1002/jmv.24789>.

FERREIRA, L.C.S; ALVES, R.P.S.; PEREIRA, L.S.; SANTOS, R.A. Sequência de ácido nucléico, antígeno recombinante, kits de diagnóstico, e usos dos mesmos.Depositante: Universidade de São Paulo. BR1020160113180, 18 may.2016, 05 dec.2017. Disponível em: https://patents.google.com/patent/WO2017197477A1/pt. Acesso em: 13 mar 2018.

FOCOSI, D.; MAGGI, F.; PISTELLO, M. Zika virus: Implications for public health. Clinical Infectious Diseases, v. 63, n. 2, p. 227-233, 2016. Disponível em: $<$ https://www.researchgate.net/publication/299941290_Zika_Virus_Implications_for_ Public_Health>.

FREIRE, C. C. M.; IAMARINO, A.; NETO, D. F. L.; SALL, A. A.; MARINHO, P.; ZANOTTO, A. Spread of the pandemic Zika virus lineage is associated with NS1 codon usage adaptation in humans. bioRxiv, v. 2015, n. August, p. 1-8, 2015. Disponível em: <https://www.biorxiv.org/content/early/2015/11/25/032839>.

KWEK, S. SEN; WATANABE, S.; CHAN, K. R.; ONG, E. Z.; TAN, H. C.; NG, W. C.; NGUYEN, et al.,; A systematic approach to the development of a safe live attenuated Zika vaccine. Nature Communications, v. 9, n. 1, 2018. Disponível em: <http://dx.doi.org/10.1038/s41467-018-03337-2>.

LEE, A. J.; BHATTACHARYA, R.; SCHEUERMANN, R. H.; PICKETT, B. E. Identification of diagnostic peptide regions that distinguish Zika virus from related mosquito-borne Flaviviruses. PLoS ONE, v. 12, n. 5, p. 1-18, 2017. Disponível em: <https://journals. plos.org/plosone/article?id=10.1371/journal.pone.0178199>.

LOWE, R.; BARCELLOS, C.; BRASIL, P.; CRUZ, O. G.; HONÓRIO, N. A.; et al.,. The zika virus epidemic in brazil: From discovery to future implications. International 
Journal of Environmental Research and Public Health, v. 15, n. 1, 2018. Disponível em: <http://www.mdpi.com/1660-4601/15/1/96>.

LUSTIG, Y.; ZELENA, H.; VENTURI, G.; ESBROECK, M. Van; ROTHE, C.; PERRET, C.; et al.,. Sensitivity and Kinetics of an NS1-Based Zika Virus EnzymeLinked Immunosorbent Assay in Zika Virus- Infected Travelers from Israel, the Czech Republic, Italy, Belgium, Germany, and Chile. Journal of Clinical Microbiology, v. 55, n. 6, p. 1894-1901, 2017. Disponível em: $<$ https://jcm.asm.org/content/55/6/1894.long $>$.

MAGALHAES, T.; BRAGA, C.; CORDEIRO, M. T.; OLIVEIRA, A. L. S.; CASTANHA, P. M. S.; et al.,. Zika virus displacement by a chikungunya outbreak in Recife, Brazil. PLoS Neglected Tropical Diseases, v. 11, n. 11, p. 1-13, 2017. Disponível em: $<$ https://journals. plos.org/plosntds/article?id=10.1371/journal.pntd.0006055>.

MUSSO, D.; GUBLER, D. J. Zika virus. Emerging infectious diseases, v. 20, n. 6, p. 1090, 2016. Disponível em: <http://www.ncbi.nlm.nih.gov/pubmed/24983096\%0Ahttp://www.pubmedcentral.nih.g ov/articlerender.fcgi?artid=PMC4036762>.

NICOLINI, A. M.; MCCRACKEN, K. E.; YOON, J. Y. Future developments in biosensors for field-ready Zika virus diagnostics. Journal of Biological Engineering, v. 11, n. 1, p. 1-9, 2017. Disponível em: <http://dx.doi.org/10.1186/s13036-016-0046-z>.

RASTOGI, M.; SHARMA, N.; SINGH, S. K. Flavivirus NS1: A multifaceted enigmatic viral protein. Virology Journal, v. 13, n. 1, p. 1-10, 2016. Disponível em: <http://dx.doi.org/10.1186/s12985-016-0590-7>.

RIBEIRO, G. S.; KIKUTI, M.; TAURO, L. B.; NASCIMENTO, L. C. J.; CARDOSO, C. W.; et al., ; Does immunity after Zika virus infection cross-protect against dengue? The Lancet Global Health, v. 6, n. 2, p. e140-e141, 2018. Disponível em: <http://dx.doi.org/10.1016/S2214-109X(17)30496-5>.

ROTH, C.; DELGADO, F. G.; SIMON-LORIÈRE, E.; SAKUNTABHAI, A. Immune responses to dengue and Zika viruses-Guidance for $T$ cell vaccine development. International Journal of Environmental Research and Public Health, v. 15, n. 2, p. 1-12, 2018. Disponível em: <http://www.mdpi.com/1660-4601/15/2/385>.

SAÚDE, M. da. Protocolo de Vigilância e Resposta à Ocorrência de Microcefalia e/ou Alterações no Sistema Nervoso Central (SNC). [s.I: s.n.]. Disponível em: $<$ http://combateaedes.saude.gov.br/images/sala-de-situacao/Microcefalia-Protocolode-vigilancia-e-resposta-10mar2016-18h.pdf>.

SBPC/ML. Posicionamento oficial da Sociedade Brasileira de Patologia Clínica/Medicina Laboratorial referente ao diagnóstico laboratorial do Zika vírusSociedade Brasileira de Patologia Clínica Medicinal Laboratorial. [s.I: s.n.]. Disponível

em:

<http://www.sbpc.org.br/upload/conteudo/sbpcml_posicionamento_zika_virus.pdf>. 
SHANKAR, A.; PATIL, A. A.; SKARIYACHAN, S. Recent perspectives on genome, transmission, clinical manifestation, diagnosis, therapeutic strategies, vaccine developments, and challenges of zika virus research. Frontiers in Microbiology, v. 8, n. SEP, p. 1-14, 2017. Disponível em: <https://www.ncbi.nlm.nih.gov/pmc/articles/PMC5603822/>.

SINGH, R. K.; DHAMA, K.; KARTHIK, K.; TIWARI, R.; KHANDIA, R.; et al.,. Advances in diagnosis, surveillance, and monitoring of zika virus: An update. Frontiers in Microbiology, v. 8, n. JAN, p. 1-17, 2018. Disponível em: $<$ https://www.frontiersin.org/articles/10.3389/fmicb.2017.02677/fulls.

WAGGONER, J. J.; PINSKY, B. A. Zika virus: Diagnostics for an emerging pandemic threat. Journal of Clinical Microbiology, v. 54, n. 4, p. 860-867, 2016. Disponível em: <https://jcm.asm.org/content/54/4/860.long>.

WHO. Current Zika Product Pipeline. Who, n. March, p. 1-16, 2016. Disponível em: $<$ http://www.who.int/blueprint/priority-diseases/key-action/zika-rd-pipeline.pdf>. 